\title{
The SMEs' Technology Acceptance of Digital Media for Stakeholder Engagement
}

By Mark Anthony Camilleri ${ }^{12}$, University of Malta, Malta AND University of Edinburgh, Scotland.

How to Cite: Camilleri, M.A. (2018). The SMEs' Technology Acceptance of Digital Media for Stakeholder Engagement. Journal of Small Business and Enterprise Development (Forthcoming).

Purpose: Small and medium sized enterprises (SMEs) are increasingly communicating and interacting with stakeholders through digital media. Therefore, this research investigates the SME owner-managers' attitudes toward the pace of technological innovation, and it examines their perceived use and ease of digital media for stakeholder engagement.

Design: The research methodology integrated measuring items from the technology acceptance model, the pace of technological innovation and corporate social responsibility (CSR), to better understand the SME owner-managers' rationale for using digital media. The respondents were expected to reveal their attitudes toward commercial, ethical and social responsibilities.

Findings: A factor analysis indicated that the SME owner-managers were perceiving the usefulness of digital media to engage with marketplace stakeholders. Whilst, a stepwise regression analysis reported positive and significant relationships between the pace of technological innovation and the SMEs' perceived usefulness of digital media for communication purposes. The results also revealed that young owner-managers from large SMEs were more likely to utilize digital media than their smaller counterparts.

Originality: This contribution implies that both small and micro businesses are utilizing digital media to improve their stakeholder engagement. This study indicates that the pace of technological innovation, the SMEs' perceived ease of use of digital media, as well as their commercial responsibility were significant antecedents for the SMEs' online communication.

Keywords: Responsible Entrepreneurship, CSR, Corporate Social Responsibility, Digital Media, Online, Social Media, TAM, Technology Acceptance Model, Pace of Technological Innovation, CSR measures.

\footnotetext{
${ }^{1}$ Department of Corporate Communication, Faculty of Media and Knowledge Sciences, University of Malta, Msida, MSD2080, Malta. Email: mark.a.camilleri@um.edu.mt

${ }^{2}$ The Business School, University of Edinburgh, Bucchleuch Place, Edinburgh, EH89JS, Scotland.
} 


\section{Introduction}

Many corporations are increasingly reporting comprehensive content on their corporate social responsibility (CSR), environmental sustainability and corporate governance issues for the benefit of their stakeholders. The stakeholder theorists, including Clarkson (1995), Donaldson and Preston (1995) and Freeman (1994), among others, argued that firms can address, balance, coordinate, and prioritize multiple stakeholder demands. Their social engagement enables them to become more efficient, reputable and successful, as they improve their financial performance (Panwar, Nybakk, Hansen and Pinkse, 2017; Orlitzky, Schmidt and Rynes, 2003). Therefore, the businesses including the small and medium sized enterprises (SMEs) are encouraged to promote their responsible behaviors, and to forge stakeholder relationships. This contribution posits that online communication has potential to create a ripple effect that grows as SMEs can reach wider audiences. Notwithstanding, relevant content that is targeted at the right stakeholders could translate into tangible benefits for the company's reputation, brand image, customer loyalty and investor confidence (Camilleri, 2017; Reijonen, 2010; Morsing and Schultz, 2006), among other benefits. As a result, it has never been more necessary to turn stakeholders into advocates for both the cause and the company (Du, Bhattacharya and Sen, 2010).

The responsible firms are capable of aligning themselves with their broader context (Panwar et al., 2017; Brammer, Jackson and Matten, 2012; Matten and Moon, 2008; Jenkins, 2006). Several empirical studies have indicated that discretionary investments in CSR, whether it is driven from strategic intents or from posturing behaviors, will still result in improved relationships with both internal and external stakeholders (Panwar et al., 2017; Reijonen, 2010; Uhlaner, Van Goor-Balk and Masurel, 2004; Orlitzky et al., 2003; McWilliams and Siegel, 2001). Hence, there is scope for the SMEs to promote their responsible entrepreneurial practices (Panwar et al., 2017; Taiminen and Karjaluoto, 2015; Baumann Pauly, Wickert, Spence and Scherer, 2013; Durkin, McGowan and McKeown, 2013). SMEs can use ICT and the Internet to (i) publicise their information on a web site (ii) interact with marketplace stakeholders through automated communications systems; and for (iii) consumer engagement (Taylor and Murphy, 2004).

This paper addresses a knowledge gap in academic literature as it examines the small firms' owner-managers' attitudes on the pace of technological innovation, and on their perceived 'use' and 'ease of use' of digital media for stakeholder engagement and for the promotion of commercial, ethical and social responsibility. 


\subsection{The Research Question}

Relevant academic literature has reported different findings on the drivers and barriers for the SMEs' engagement with digital media (Taiminen and Karjaluoto, 2015; Durkin et al., 2013; Taylor and Murphy, 2004). Previous studies suggested that many SMEs are not benefiting enough of the digital tools' full potential (Taiminen \& Karjaluoto, 2015). The SMEs may not consider the use of digital media as an effective marketing communications channel to promote products and services. Very often, SMEs serve small, niche markets, thus, they may not always use the Internet for their digital marketing (Sin Tan, Choy Chong, Lin \& Uchenna, 2010; Shah Alam, 2009). The small businesses often rely on advertising and promotions in their local markets. Moreover, the SME owner-managers may be concerned on their security and privacy issues, as they may be wary of making online transactions (Gupta, Seetharaman \& Raj, 2013). Alternatively, they lack the necessary confidence and skills to engage with their online prospects (Durkin et al., 2013), or may not have the time and resources to use digital media (Brouthers, Nakos \& Dimitratos, 2015).

Therefore, the purpose of this study is to examine the SME owner-managers' attitudes toward digital media. They could use this interactive technology as a vehicle for stakeholder engagement purposes and to promote their responsible entrepreneurship practices. This study involves a quantitative methodology that integrates valid and reliable measures from the 'pace of technological innovation' (Garcia and Calantone, 2002), 'technological anxiety' (Greenhow and Robelia, 2009; Grewal, Mehta, and Kardes, 2004), and has utilized items from 'the technology acceptance model' (Rauniar, Rawski, Yang and Johnson, 2014; Davis, 1989) to explore the respondents' attitudes toward digital media. In addition, this contribution investigates the SME owner-managers' attitudes on their stakeholder engagement and CSR behaviors. Uhlaner et al. (2004) posited that the small business owners might consider forging good relationships with employees, clients, and suppliers, as they reported that these stakeholders are closely tied to their business. Hence, the researcher has adapted Singh and Del Bosque's (2008) CSR measures that comprised commercial, ethical and social responsibility aspects.

Specifically, the objective of this contribution is to reveal the SME owner-managers' stance toward technological innovation; and to determine whether they intend to use digital media for stakeholder engagement as well as for commercial, ethical and social responsibility reporting. 


\section{Theoretical Background and the Formulation of Hypotheses}

\subsection{Responsible Entrepreneurship and Stakeholder Engagement}

Where SMEs are concerned, there seems to be a problem with the adopted terminology involving corporate social responsibility. SMEs are not corporations. It is unlikely that SMEs would use any recognizable language of CSR, including the acronym itself (Murillo and Lozano, 2006). However, the CSR terminology has become the dominant refrain in this subject area (see Panwar et al., 2017; Perrini, Russo and Tencati, 2007; Uhlaner et al., 2004). Although it is worth noting that the phrases; 'responsible business' (Moore and Spence, 2006), 'responsible entrepreneurship' (Fuller and Tian, 2006) and 'social capital' (Russo and Perrini, 2010; Spence and Schmidpeter (2003) have also gained momentum in academic literature.

Bacon, Ackers, Storey and Coates, (1996:83) noticed that the small firms were experimenting with new management initiatives, such as; culture change, devolved management, team working, flexibility and quality task forces. Sound empirical evidence has shown that SMEs were taking up best practice ideas that were adopted by the larger firms (Russo \& Perrini, 2010). Eventually, Storey, Emberson, Godsell and Harrison (2006) presumed that a significant factor for the SMEs' engagement in responsible behaviors was that good practices were becoming embedded in their supply chain relationships (Uhlaner et al., 2004). Furthermore, there was mounting pressure from third parties, as they demanded that SMEs should also follow online and offline networking behaviors of their larger counterparts (see Harris, Rae and Misner, 2012). However, SMEs possess distinctive characteristics of informality (Russo and Perrini, 2010). Therefore, the processes that trigger the employees' involvement in such enterprises may need to be identified against other factors that are relevant to particular organizational contexts. For instance, the nature of the SMEs' small social setting can provide them with an opportunity for enhanced flows of communication, more face-to-face involvement and flexibility in managing human resources. The smaller firms and their practices are usually portrayed contextually, subjectively and/or in interpretational ways (Camilleri, 2015).

The small business entrepreneurs may have reservations about the responsible behavioral methods of the larger businesses (Fassin, 2008). Whilst the larger corporations support the philosophy behind their CSR, the small business practitioners tend to express their doubts about the sincerity of their larger counterparts (Jenkins, 2006). Notwithstanding, the smaller firms may be opposed to the extra administrative burdens in their daily routines. Baumann Pauly et 
al. (2013) maintained that the consistent handling of CSR in MNCs required them to draft formal CSR policies and procedures. However, embedding CSR policies and procedures globally, and in all daily operations is an enormous task for MNCs. Hence, rolling out a CSR policy takes time and resources. The reality is that CSR is different for SMEs than it is for the larger firms, for the very same reason that sets their operations apart (Russo and Perrini, 2010; Uhlaner et al., 2004). Whilst, the corporations are more likely to address environmental sustainability and social responsibility issues, as they are more active in their engagement with internal and external stakeholders (Camilleri, 2017); the SMEs often demonstrate a genuine commitment towards their community and society at large (Perrini et al., 2007). The enterprises' owner-managers may conduct their business activities with a conscience, as they are concerned about their responsible and sustainable behaviors (Jenkins, 2006). They frequently do this without referring to the CSR concept at all, and without communicating what they do (Fassin, 2008).

Russo and Tencati (2009) have evidenced the small firms' aptitude toward CSR initiatives. The authors revealed how the firms' strategies were making a significant impact on their bottom line. They noted that there was a genuine commitment for eco-efficiency (i.e. reduction of consumption and pollution prevention). Moreover, they have shown how micro firms supported initiatives that encouraged stakeholder engagement. This issue exemplifies the responsible enterprises' attempt to secure a social license to operate in their respective communities. This research perspective suggests that the SMEs are subject to a number of distinctive and intrinsic characteristics that set them apart from the larger firms. These characteristics contribute to influence the content, nature and extent of their social and environmentally responsible activities.

Spence (2007) has gathered a considerable amount of academic work about European SMEs. While these factors are probably not limited to Europe, a wide array of other literature (Baumann Pauly et al., 2011; Perrini et al., 2007; Fuller, 2006) have also recommended further research on the responsible behaviors of SMEs. Other research is increasingly focusing on the issues of CSR reporting (Camilleri, 2015), and stakeholder dialogue (e.g. Tantalo and Priem, 2016). Relevant studies have indicated that the communication of social responsibility practices among SMEs is generally unsystematic and handled in an ad-hoc manner (Fassin, 2008). Yet, it may be presumptuous to generalize that all SMEs are not communicating their responsible behaviors. Many SMEs are increasingly realizing that they may enhance their reputation and standing if they disclose their good practices to stakeholders. There are 
opportunities for them to create good publicity, as they can also raise awareness of their brand and products. Therefore, there is scope for SMEs to improve their stakeholders' relations through the application of appropriate social and environmental reporting (Camilleri, 2015; Fassin, Van Rossem and Buelens. 2011; Fassin, 2008).

Lately, there were significant improvements in the corporations' non-financial disclosures in integrated reports, that are auditable through regulatory instruments (such as the Global Reporting Initiatives, Integrated Reporting Framework, Social Accountability, et cetera). Previously, some academic commentators have raised their concerns about the issues of communicating CSR. The bone of contention lies with the SMEs' formalization of their responsible entrepreneurship (Fassin, 2008; Uhlaner et al., 2004). As SMEs might not always report their responsible entrepreneurship and stakeholder engagement, one might erroneously conclude that it is non-existent for them. However, relevant literature suggests that social and environmental disclosures are a necessary requirement, in this day and age. The obligation of online reporting encourages reflection, as it helps to awaken the organization, to make its responsible actions visible to stakeholders, and to a certain extent measurable, as well (Perrini et al., 2007). The administrative burden for the communication of CSR can be weighed against a cost-benefit analysis (McWilliams and Siegel, 2001; Orlitzky, Siegel, and Waldman, 2011). In this context, the SMEs may be restrained to report about their responsible entrepreneurship behaviors as they possess scarce resources and capabilities to formalize their social and environmental disclosures through digital media (Penwar et al., 2017; Fassin et al., 2011).

\subsection{The Technological Innovation, Perceived Use and Ease of Use of Digital Media}

The technological innovation can be defined as the application of better solutions that meet new requirements, unarticulated or existing market needs (Maranville, 1992). Therefore, technological innovation (including digital media) can provide economic value through the adoption and diffusion (Garcia and Calantone, 2002) of new products. Alternatively, it may involve continuous improvements or upgrades of existing products and services. For instance, digital media has enabled the emergence of a new participatory public sphere where everybody could dialogically interact and collaborate in the co-creation of content (Lamberton and Stephen, 2016; Colleoni, 2013; Durkin et al., 2013; Kaplan and Haenlein, 2010). The immediate engagement in real-time between the public and the organization is one of the main characteristics of the internet. Online users are continuously being presented with the companies' content marketing as the global diffusion of social software like blogs, wikis, 
electronic fora, webinars and social media networks have facilitated the organizations' interaction with stakeholders (Camilleri, 2017).

Many corporate websites already possess a high degree of interactivity; with their ability to disseminate information and to generate relationships between different publics and the organization (Capriotti and Moreno, 2007). The use of the Internet can be unidirectional when it diffuses information. However, social media platforms facilitate interactions as they are characterized by two-way communications between the organization and its stakeholders. Therefore, online platforms have led to a symmetric engagement between participants, and have eliminated formal hierarchies (Castelló, Morsing and Schultz, 2013). In addition, there is a lack of gatekeeping in social media (Morsing and Schultz, 2006; Vorvoreanu, 2009). For this reason, interactive communication is changing the social dynamics (Harrigan and Miles, 2014; Fieseler and Fleck, 2013). The Web and data exchanges have empowered the communication between businesses and their stakeholders. The Internet enables them to engage with online users and to take advantage of positive publicity arising from real-time, word-of-mouth marketing (Camilleri, 2017).

Communication through social media is dynamic in relation to traditional media (Lamberton and Stephen, 2016; Taiminen and Karjaluoto, 2015; Rauniar et al., 2014). Social media have the technological potential to speed up communication processes (Kaplan and Haenlein, 2010) and to increase direct interaction, dialogue and participation across organizations and various audiences (Colleoni, 2013; Schultz, Utz and Göritz, 2011). Such interactive communications are often referred to as "viral" because ideas and opinions spread like epidemic diseases through the network via word-of-mouth. These channels are perceived as highly trustworthy sources (Schultz and Wehmeier, 2010). Hence, when SMEs share information with online communities on their responsible entrepreneurship and stakeholder engagement, they may find out that their followers (or friends) may also share their passion for good causes. However, there are many plausible reasons why the communicative features that are enabled by digital media may not be employed as efficiently by the businesses' marketers (Tiago and Veríssimo 2014; Kaplan and Haenlein, 2010). For this reason, the SME owner-managers are encouraged to acquaint themselves with the use of digital media in order to increase the impact of their communications. There is an opportunity for them to use interactive technologies to increase the frequency, reach and impact of their messages (Kaplan and Haenlein, 2010). The SME executives are in a position to amplify the effectiveness of their responsible entrepreneurship efforts through digital media. However, they should decide what to communicate (i.e. message 
content) and where to communicate (i.e. message channel) to reach out to different stakeholders.

In sum, the Web is currently advancing at an unprecedented pace of technology. Its online communities have already transformed the Internet through innovative, highly scalable, social media networks and product recommender systems. The emergence of user-generated content in fora, newsgroups, social media and crowd-sourcing have also offered endless opportunities for both researchers and practitioners to "listen" attentively to stakeholders, including; customers, employees, suppliers, investors, regulatory authorities and the media, among others. The premise is that the digital media improves the efficiency of the organizations' engagements with stakeholders. Yet, recent contributions suggest that the implementation of the businesses' online engagement is neither automatic nor easy (Tiago and Veríssimo, 2014; Besiou, Hunter, and Van Wassenhove, 2013; Etter, 2013). The dialogic features that are enabled by web pages, blogs, and other social media may prove difficult to apply (Etter, 2013; Moreno and Capriotti, 2009). Recent research has discussed about the dialogic aspects of online stakeholder engagement (Moreno and Capriotti, 2009). Yet, little empirical research has measured the enterprises' owner-managers stance on communicating about commercial, ethical and social responsibility issues through digital technologies.

\subsection{The Formulation of Hypotheses}

This study has investigated the owner-managers' attitudes toward their 'technology acceptance" for digital media (Greenhow and Robelia, 2009; Grewal et al., 2004; Garcia and Calantone, 2002). The respondents were expected to indicate their behavioral intention on the "use" and "ease of use" (Davis, 1989) of digital media. This study has adapted "the pace of technological innovativeness" measure, as its items provided an opportunity to examine the respondents' engagement with ubiquitous technologies, including the Internet and social media, among others. This measure explored how practitioners were keeping themselves up to date with the latest digital media (Greenhow and Robelia, 2009), in order to interact with stakeholders and to promote their responsible entrepreneurial activities. This argumentation leads to the first two hypotheses:

(i) There is a positive relationship between "the pace of technological innovation" and the entrepreneurs' perceived "usefulness" and "ease of use" of digital media. 
(ii) There is a positive relationship between "the pace of technological innovation" of digital media and the owner-managers' stakeholder engagement through online reporting of responsible entrepreneurial practices.

The technology acceptance model (TAM) has often explained the users' adoption behaviors of technology (Rauniar et al., 2014). TAM suggests that there is a causal relationship between the users' attitudes and their behavioral intention to use technology. In the past, TAM sought to explain why people accept or reject a particular technological innovation (Davis, 1989). In this light, this model has been purposely chosen to determine why SMEs were accepting or rejecting the use of digital media for stakeholder engagement and CSR disclosures. The perceived usefulness of digital media is the degree to which a person believes that using this technology would enhance his or her job performance in marketing communications (Reijonen, 2010; Davis, 1989). From the outset, the researcher presumed that the owner-managers would perceive the "usefulness" of digital media (to communicate their CSR credentials to stakeholders). TAM also comprises the perceived "ease of use" construct, which is the degree to which a person believes that using a particular system (including websites, search engine optimization, social media, blogs, et cetera) would be free from effort. The usage of such online technologies is influenced by the perceived "ease of use" (Davis, 1989). Therefore, this study hypothesized;

(iii) There is a positive relationship between perceived "usefulness" and the perceived "ease of use" of digital media.

Although potential users may believe that a given innovation is useful; they may, at the same time be wary of digital media. The owner-managers may not possess digital skills and competencies to engage with online prospects. Alternatively, they think that online technologies may be too hard to use, and that their performance benefits are outweighed by the effort of using such applications (Meuter, Bitner, Ostrom and Brown, 2005). Therefore, they will not dedicate sufficient time and resources to use the digital media. As a result, companies may not always report adequate and significant information on their commercial, ethical, social responsibility and environment-related activities (Singh and Del Bosque, 2008). However, a thorough literature review suggested that there is scope for companies of all sizes to engage in continuous online communications with stakeholders, including; suppliers and consumers (Tantalo and Priem, 2016; Du et al., 2010; Perrini et al., 2009; Jenkins, 2006). Well-known brands are usually visible online, and they even communicate about their CSR engagement. 
Yet, there are still a number of companies' that are not reaping the benefits of digital media usage. This leads to the fourth hypothesis that aims to identify the possible antecedents (by using a stepwise regression analysis) for online stakeholder engagement.

(iv) The "pace of technological innovation", the owner-managers" "perceived usefulness" and "ease of use" of digital media, and their "responsible entrepreneurship behaviors" (including their commercial, ethical and social responsibilities) are the antecedents for the owner-managers' stakeholder engagement through digital media.

This last hypothesis has adopted the digital media measures of technological innovation, technology acceptance, technological anxiety as well as the CSR items that examined the owner-managers' attitudes toward commercial, ethical, and social responsibilities.

\section{Methodology}

The survey questionnaires were distributed by email to SME owner-managers who were members in a trade union representing the retail and hospitality industries. These participants were informed in writing about an academic research on the use of digital media among enterprises. Moreover, the researcher has promoted this study during an annual meeting with the trade union members. As a result, there was a response rate of 51\% $(n=202)$ from all the targeted enterprises in a small European Union country. The rationale behind the selection of the designated profile of owner-managers was to gain a good insight into their ability to make evaluative judgements on their enterprises' online stakeholder engagement and responsible entrepreneurship initiatives. Table 1 presents the socio-demographic profile of the sample: 


\begin{tabular}{|c|c|c|c|}
\hline \multicolumn{4}{|c|}{ Table 1. The socio demographic profile of the survey participants } \\
\hline \multicolumn{2}{|l|}{ Age } & \multicolumn{2}{|l|}{ Gender } \\
\hline Less than 19 years & 2 & Male & 87 \\
\hline Between 20 to 29 years & 47 & Female & 115 \\
\hline Between 30 to 39 years & 57 & $(n=202)$ & \\
\hline Between 40 to 49 years & 43 & Firm Size & \\
\hline Between 50 to 59 years & 27 & 1 to 10 Employees & 71 \\
\hline Between 60 to 69 years & 17 & 11-50 Employees & 92 \\
\hline Over 70 years & 8 & 51-250 Employees & 39 \\
\hline $\begin{array}{l}\text { mean: } \\
(n=201)\end{array}$ & 37.1 years & $(n=202)$ & \\
\hline \multicolumn{2}{|l|}{ Education } & & \\
\hline Secondary & 13 & & \\
\hline Post-Secondary / Vocational & 123 & & \\
\hline Undergraduate & 45 & & \\
\hline Post Graduate & 18 & & \\
\hline$(n=199)$ & & & \\
\hline
\end{tabular}

\subsection{The Measures for Digital Media}

The researcher has adapted six items from the 'pace of technological innovation' that measured the practitioners' perceptions on technological change in digital media. Originally, this scale reported a construct reliability of 0.97 (Grewal et al., 2004) and had used confirmatory factor analysis to provide evidence to support the scales' convergent and discriminant validities. This study has also used the technology acceptance model to explore the respondents' attitudes on web technologies (Davis, 1989). This model has become a popular means by which to evaluate the users' attitudes on their perceived 'ease of use' and 'usefulness' toward technological innovation, as well as on their behavioral intention (Davis, 1989). Originally, the perceived 'use' six-item scale attained a construct reliability of 0.97 , while the perceived 'ease of use' six-item scale achieved a reliability of 0.91 (Davis, 1989). These scales were considered acceptable as the factor loadings were significant and there was evidence of discriminant validity for each construct. Four items relating to 'technological anxiety' were used to measure the owner-managers' degree of apprehension toward the use of digital media (Lamberton and Stephen, 2016; Taiminen and Karjaluoto, 2015; Rauniar et al., 2014; Meuter et al. 2005). The original measure reported a Cronbach's Alpha of 0.93 (Meuter et al., 2005). This measure was acceptable as the factor loadings were reported to be significant. There was evidence of 
discriminant validity for each construct (as the confidence interval and the variance were extracted).

\subsection{The Measures for Responsible Entrepreneurship}

Many businesses are increasingly engaging in responsible behaviors (Panwar et al., 2017; Spence, 2007; Uhlaner et al., 2004). Very often, they are even disclosing their environmental, social and governance information on their web pages (Russo and Perrini, 2010). Therefore, this study has adapted Singh and Del Bosque's 'commercial', 'ethical', 'social' and 'support to responsible stakeholders' dimensions that consisted of 16 items. With respect to scale reliability, the Cronbach's Alpha and the composite reliability coefficients were above the minimum acceptance value of 0.7. Moreover, all standardized lambda values were statistically significant and above 0.5 .

The 'commercial' dimension measured the owner-managers' perceptions about their economic strategy. The 'ethical' dimension featured items on ethics and regulatory matters. It explored the respondents' attitudes about honesty, integrity and moral principles. The 'social' dimension referred to environmental protection and to discretionary investments in the community. The 'support to responsible stakeholders' dimension sought to discover how the respondents perceived corporate communications on commercial, ethical and social issues (Singh and Del Bosque, 2008).

\section{Data Analysis}

Firstly, the descriptive statistics have illustrated the means and standard deviations for all variables. Secondly, a principal component analysis (PCA) has been chosen to obtain a factor solution of a smaller set of salient variables. Thirdly, a multivariate regression analysis has investigated the hypothesized associations by using the stepwise procedure.

\subsection{Descriptive Statistics}

All responses were coded using a five-point Likert scaling mechanism. The values ranged from 1 (strongly disagree) to 5 (strongly agree), whereas 3 signaled an indecision. The measuring items that were used in this study included; "the pace of technological innovation"”, the technology acceptance model's 'perceived ease of use', 'perceived usefulness', and 'technological anxiety', as well as CSR measures relating to 'commercial responsibility', 'ethical responsibility', 'social responsibility', and "support to responsible stakeholders" are presented in Table 2. 


\begin{tabular}{|c|c|c|c|}
\hline $\begin{array}{l}\text { Pace of Technological } \\
\text { Innovation }\end{array}$ & Items & Mean & $\begin{aligned} \text { Std } \\
\text { Dev. }\end{aligned}$ \\
\hline \multirow{6}{*}{$\begin{array}{l}\text { Grewal, Mehta and Kardes } \\
\text { (2004) }\end{array}$} & Digital Media is changing at a very fast pace. & 4.03 & 0.53 \\
\hline & $\begin{array}{l}\text { Compared to other integrated marketing communication, digital } \\
\text { media is changing fast. }\end{array}$ & 3.42 & 0.46 \\
\hline & $\begin{array}{l}\text { I have consistently seen new digital media technologies for some } \\
\text { time. }\end{array}$ & 3.95 & 3.37 \\
\hline & Innovations in digital media are frequent. & 3.68 & 3.53 \\
\hline & The pace of technological innovations in digital media is high. & 3.2 & 0.47 \\
\hline & $\begin{array}{l}\text { Technological innovations and integrated marketing } \\
\text { communications don't go hand in hand. }\end{array}$ & 2.19 & 0.71 \\
\hline Perceived Ease of Use & e & Mean & $\begin{array}{l}\text { Std } \\
\text { Dev. }\end{array}$ \\
\hline \multirow{6}{*}{$\begin{array}{l}\text { Davis (1989); Meuter, Bitner, } \\
\text { Ostrom and Brown (2005) }\end{array}$} & Learning to operate digital media would be easy for me. & 3.82 & 0.58 \\
\hline & $\begin{array}{l}\text { I would find it easy to use digital media for corporate } \\
\text { communication. }\end{array}$ & 3.21 & 0.53 \\
\hline & $\begin{array}{l}\text { My interaction with the digital media would be clear and } \\
\text { understandable for my stakeholders. }\end{array}$ & 3.86 & 0.34 \\
\hline & I would find digital media to be flexible to interact with. & 3.81 & 0.4 \\
\hline & It would be easy for me to become skilful at using digital media. & 3.86 & 0.53 \\
\hline & I would find digital media resources easy to use. & 3.95 & 0.39 \\
\hline Perceived Usefulness & Items & Mean & $\begin{array}{l}\text { Std } \\
\text { Dev. }\end{array}$ \\
\hline \multirow{6}{*}{$\begin{array}{l}\text { Davis (1989); Meuter, Bitner, } \\
\text { Ostrom and Brown (2005) }\end{array}$} & $\begin{array}{l}\text { Using digital media would enable me to accomplish corporate } \\
\text { communication tasks more quickly. }\end{array}$ & 3.78 & 0.41 \\
\hline & Using digital media would improve my communication. & 3.96 & 0.38 \\
\hline & $\begin{array}{l}\text { Using digital media would enhance my effectiveness in integrated } \\
\text { marketing communication. }\end{array}$ & 3.91 & 0.28 \\
\hline & $\begin{array}{l}\text { Using digital media would make it easier to do my corporate } \\
\text { communications. }\end{array}$ & 3.99 & 1.25 \\
\hline & I would find digital media resources useful in my job. & 3.95 & 0.34 \\
\hline & Learning to operate digital media resources would be easy for me. & 3.78 & 1.41 \\
\hline Technological Anxiety & Items & Mean & $\begin{array}{l}\text { Std } \\
\text { Dev. }\end{array}$ \\
\hline \multirow{4}{*}{$\begin{array}{l}\text { Meuter, Bitner, Ostrom and } \\
\text { Brown (2005) }\end{array}$} & I feel apprehensive about using digital media. & 2.71 & 0.45 \\
\hline & Technical terms sound like confusing jargon to me. & 2.88 & 0.44 \\
\hline & I have avoided digital media because it is unfamiliar to me. & 2.34 & 0.53 \\
\hline & $\begin{array}{l}\text { I hesitate to use most forms of technology for fear of making } \\
\text { mistakes I cannot correct. }\end{array}$ & 1.9 & 0.29 \\
\hline
\end{tabular}

This study is consistent with the extant literature on the 'technology acceptance model' (Davis, 1989, Meuter et al., 2005). As a matter of fact, there were high mean scores of near 4 , which 
reflected the respondents' stance on the use of digital media. Moreover, the survey participants have indicated their strong agreement with the 'pace of technological innovation' (Grewal et al., 2004). The owner-managers suggested that digital media is continuously changing; the mean score was of 4.03 , and there was a standard deviation of 0.87 . They also suggested that integrated marketing communications relies on technological innovation (in the negatively worded item). Generally, the research participants indicated that they were not apprehensive toward digital technologies (Meuter et al., 2005). They findings revealed that they did not hesitate to use different technologies for fear of making mistakes; the mean was 1.9, and the standard deviation was 0.29 .

The participants strongly agreed with the statements pertaining to the commercial responsibility of their business. The mean scores were all higher than 4 . This finding suggests that the owner-managers felt that they were providing a high-quality service to their customers. They also indicated that they were acting in a fair and honest manner with stakeholders. In this case, the mean was 4.07 , and the standard deviation was 1.19 . The survey participants were committed to fulfil their legal obligations. The results suggest that they respected the human rights and ethical norms. Apparently, this respect had priority over achieving superior economic performance, where the mean was 3.94, and the standard deviation was 1.22. Moreover, the owner-managers were also concerned on social issues (mean was 3.34 and standard deviation was 1.24) and environmental responsibility (mean was 3.46, standard deviation was 1.64). Yet there were low attitudinal scores on philanthropy and stewardship towards disadvantaged groups and individuals (mean was 2.43 and standard deviation was 0.47). The results also indicated that the owner-managers were not so committed to financing social and cultural activities (mean was 2.56 and the standard deviation was 0.94 ). The survey respondents indicated that they pledged their support toward responsible suppliers. However, they were not willing to pay more to buy products from ethical and socially responsible companies (where the mean was 2.12, and the standard deviation was 0.87 ).

This study investigated how 'gender' and 'age' could influence the frequency of use of digital media. The results indicated that gender did not influence this choice as there was no statistically significant difference between the groups' means as determined by the Chi square tests. This study reported that 83 males and 113 females (there were six missing values) used digital media on a daily basis. Pearson's Chi-Square $\chi 2$ : was 1.150 , Df 2. $p=0.563$. This finding suggested that gender did not significantly influence the frequency of use of digital media. There were no statistically significant differences between different age groups and the 
frequency of use of digital technology. However, the results showed that the survey participants who were between 30 to 39 years of age (where $n=57$ ), who were followed by those who were between 20 to 29 years old (where $n=47$ ) were more likely to use their digital media than other groups. Pearson's Chi-Square $\chi^{2}$ was 3.803, Df 6 and $p=0.703$. Surprisingly, there were also a few owner-managers who have never used digital media in the past $(n=5)$.

\subsection{Data Reduction}

Bartlett's test of sphericity revealed sufficient correlation in the dataset to run a principal component analysis (PCA) since $p<0.001$. PCA has identified the patterns within the data and expressed it by highlighting the relevant similarities (and differences) in each and every component. In the process, the data has been compressed as it was reduced in a number of dimensions without much loss of information. PCA has produced a table which illustrated the amount of variance in the original variables (with their respective initial eigenvalues) that were accounted for by each component. A varimax rotation method was used to spread variability more evenly amongst the constructs. There was a percentage of variance column which indicated the expressed ratio as a percentage of the variance (this was accounted for by each component in all of the variables). Only principal components with eigenvalues greater than 1 were extracted. Table 3 illustrates the number of extracted components from the original number of variables and presents the resulting cumulative percentage of variance for the group of variables (and also reports the related 'loss of information').

Table 3 Data Reduction through Principal Component Analysis

\begin{tabular}{|l|c|c|c|c|}
\hline \multicolumn{2}{|c|}{ Original Number of Variables } & $\begin{array}{c}\text { Cumulative } \\
\text { Percentage of } \\
\text { Variance \% }\end{array}$ & $\begin{array}{c}\text { Loss of } \\
\text { Information } \\
\%\end{array}$ & $\begin{array}{c}\text { Components } \\
\text { Extracted }\end{array}$ \\
\hline Digital Media & 22 & 62 & 38 & 6 \\
\hline $\begin{array}{l}\text { Responsible Entrepreneurship } \\
\text { and Stakeholder Engagement }\end{array}$ & 12 & 74 & 26 & 4 \\
\hline
\end{tabular}

All constructs were analyzed for internal consistency by using Cronbach's alpha. There were excellent measures that exceeded the recommended reliability estimates. The value of the Kaiser Meyer Olkin (KMO) measure of sampling adequacy was also very acceptable at 0.8 . The factors accounted for more than $62 \%$ variance before rotation for the digital media variables. Whereas, the results suggested that there was $74 \%$ of the variance before rotation for 
the CSR measure. There were ten extracted components from the original thirty-nine variables for the digital media and CSR variables. A brief description of the extracted factor components, together with their eigenvalue and their respective percentage of variance is provided hereunder in Tables 4 and 5.

Table 4 The Extracted Factor Components from the Digital Media Variables

\begin{tabular}{|c|l|c|c|}
\hline & Use of Digital Media & \multicolumn{2}{|c|}{ Initial Eigenvalues } \\
\cline { 2 - 4 } & Total & $\begin{array}{c}\text { \% of } \\
\text { Variance }\end{array}$ \\
\hline 1 & Perceived Usefulness of Digital Media & 5.533 & 25.152 \\
\hline 2 & Pace of Technological Innovation & 2.378 & 10.809 \\
\hline 3 & Technological Anxiety & 1.846 & 8.391 \\
\hline 4 & Easy Interaction with Digital Media & 1.662 & 7.553 \\
\hline 5 & Perceived Ease of Use of Digital Media & 1.192 & 5.418 \\
\hline 6 & Effective Use of Digital Media & 1.119 & 5.085 \\
\hline
\end{tabular}

Extraction Method: PCA

Alpha $=0.802 ; \mathrm{KMO}=0.792 ; \mathrm{Sig}: 000$

Table 5 The Extracted Factor Components from the Responsible Entrepreneurship and Stakeholder Engagement Variables

\begin{tabular}{|c|c|c|c|}
\hline \multirow{2}{*}{} & \multicolumn{2}{|c|}{ CSR Reporting } & \multicolumn{2}{c|}{ Initial Eigenvalues } \\
\cline { 3 - 4 } & & Total & $\begin{array}{c}\text { \% of } \\
\text { Variance }\end{array}$ \\
\hline 1 & Engagement with Marketplace Stakeholders & 8.874 & 35.024 \\
\hline 2 & Online Reporting of Responsible Entrepreneurship & 4.654 & 20.119 \\
\hline 3 & Online Environmental Sustainability Reporting & 1.846 & 13.454 \\
\hline 4 & Engagement with Human Resources & 1.162 & 5.403 \\
\hline
\end{tabular}

Extraction Method: PCA

Alpha $=0.845 ; \mathrm{KMO}=0.812 ;$ Sig: .000

The factor components were labelled following a cross-examination of the variables with the higher loadings. Typically, the variables with the highest correlation scores had mostly contributed towards the make-up of the respective components. The underlying scope of 
combining the variables by using component analysis was to reduce the data and to make it more adaptable for the regression analysis.

\subsection{Regression Analysis}

This section examines the four hypothesized relationships by using multivariate regression analysis. A stepwise procedure was chosen to select the most significant predictive variables in the regression equations. Therefore, the $p$-value was set at less than the 0.05 benchmark. This also resulted in adequate F-ratios, implying that only the significant amounts of variation in regression were accounted for. More importantly, in the stepwise procedure the insignificant variables were excluded without appreciably increasing the residual sum of squares. The regression models produced the regression coefficients which represented the strength and the significance of the relationships. Moreover, the socio-demographic control variables, including; "age", "gender", "education" and "firm size" were also entered into the regression equations.

H1: The first hypothesis indicated that there was a relationship between the pace of technological innovation' and 'technological acceptance' on the use of digital media. The results indicated that there was a positive and significant relationship between 'perceived usefulness' of digital media and 'the pace of technological innovation' where Spearman's rho, adj $\mathrm{r} 2=0.173$. This relationship was significant at $(p<0.05)$. The findings suggested that the 'perceived usefulness' was dependent on 'the pace of technological innovation' (t-value = 4.457).

$\mathrm{H} 2$ : The second hypothesis explored the correlation between 'the technological innovation of digital media' with the factor component; namely, 'online reporting of responsible entrepreneurship'. The results indicated that there were positive and very significant relationships ( $p<0.01$ ); where Spearman's rho, adj r2 $=0.296$. The small businesses' 'online disclosures on their stakeholder engagement' were correlated with 'the technological innovation of digital media' $(\mathrm{t}$-value $=2.53)$ and also with 'firm size' $(\mathrm{t}$-value $=1.87)$.

H3: The third hypothesis explored the correlation between the owner-managers' perceived 'use' with their 'ease of use' of digital media. The results indicated that there were positive and very significant relationships $(p<0.01)$; where Spearman's rho, adj r2 $=0.296$. Evidently, the owner-managers were using interactive technology to communicate with their stakeholders, and they were proficient in it $(\mathrm{t}$-value $=2.53)$. The findings from the stepwise regression 
analysis also suggested that the larger firms were more likely to utilize digital media than their smaller counterparts $(\mathrm{t}-\mathrm{value}=1.87)$.

H4: The last hypothesis investigated whether the technology acceptance of digital media and the companies' ethos on responsible behaviors would have an effect on their stakeholder engagement. Therefore, the perceived 'usefulness', 'ease of use', 'the pace of technological innovation' and 'technological anxiety'; as well as their 'commercial responsibility', 'ethical responsibility', 'social responsibility' and 'support to responsible stakeholders' were all considered as plausible independent variables in the regression equation. The factor component, 'online reporting of responsible entrepreneurship' was inserted as the outcome variable. The findings reported a positive and significant relationship where Spearman's rho, adj $\mathrm{r} 2$ was 0.230 . The regression equation indicated that the small businesses' 'online stakeholder engagement' was dependent on the easy interaction with digital media (perceived 'ease of use'), where $t=6.501$; the users' digital skills ('the pace of technological innovation') where $\mathrm{t}=4.022$; 'commercial responsibility', where $\mathrm{t}=1.855$; 'firm size', where $\mathrm{t}=0.877$; apprehension of digital media ('technological anxiety'), where $t=-0.126$ and 'age', where $t=$ -0.114 .

\section{Discussion}

This contribution sheds light on the SME owner-managers' attitudes toward the pace of technological innovation, perceived use and ease of use of digital media; as they communicate and interact with interested stakeholders online. It also explored their stance on responsible entrepreneurship, specifically on commercial, ethical and social responsibilities, as well as on their willingness to support other responsible stakeholders. This empirical study and its theoretical underpinnings contribute to an improved understanding as to why today's SMEs are expected to communicate with stakeholders through digital media. At the same time, it raises awareness of responsible entrepreneurial initiatives that could be promoted through digital media, including; corporate websites, social media and blogs, among others.

Generally, the results reported that there were high mean scores and low standard deviations, particularly when the participants were expected to indicate their attitudes on their commercial and ethical responsibilities. The nature of the SMEs' CSR activities is usually integrated into their company culture, often implicitly in habits and routines that are inspired by highly motivated owner-managers; rather than explicitly in job descriptions or formalized procedures (Jenkins, 2006). The factor analysis indicated that the SME owner-managers were increasingly 
perceiving the usefulness of digital media to engage with marketplace stakeholders, including; consumers, suppliers and other businesses, as they promoted their responsible entrepreneurship behaviors. The communications on their businesses' social responsibility and environmentallysound practices also served them well to engage with other interested groups; including; human resources, shareholders and investors, among others. This finding mirrors Baumann Pauly et al.'s (2013) argumentation as these authors remarked that each business decision on economic, social, and environmental aspects must take into account all stakeholders. Notwithstanding, the businesses and their marketers need to possess relevant knowledge on their stakeholders, as this will impact on the effectiveness of their CSR communication (Morsing and Schultz, 2006; Vorvoreanu, 2009). The value of their communications lies in their ability to open-up lines of dialogue through stories and ideas that reflect their stakeholders' interests (Fieseler and Fleck, 2013; Moreno and Capriotti, 2009). For these reasons, companies cannot afford to overstate or misrepresent their CSR communications. Their online communication with stakeholders could foster positive behaviors or compel remedial actions, and will pay off in terms of corporate reputation, customer loyalty and market standing (Tantalo and Priem, 2016; Du et al, 2010).

This study suggests that the SME owner-managers were recognizing that they had to keep up with the pace of technological innovation. Yet there were a few participants, particularly the older ones, who were still apprehensive toward the use of digital media. Eventually, these respondents should realize that it is in their interest to forge relationships with key stakeholders (Lamberton and Stephen, 2016; Taiminen and Karjaluoto, 2015; Rauniar et al., 2014; Uhlaner et al., 2004). This research posits that the owner-managers or their members of staff should possess relevant digital skills and competences to communicate online with interested parties. Likewise, Baumann Pauly et al., (2013) also recommended that the managers must be trained, and that their CSR activities must be evaluated. These findings are in line with other contributions (Spence and Perrini, 2011; Perrini et al., 2007) that have theoretically or anecdotally challenged the business case perspective for societal engagement (Penwar et al., 2017; Baden and Harwood 2013; Brammer et al. 2012).

The regression analysis has identified and analyzed the determinants which explain the rationale behind the SME owner-managers' utilization of digital media for stakeholder engagement and for the promotion of responsible entrepreneurship. It reported that the respondents' technology acceptance depended on their perceived "use" and "ease of use" of digital media; and on their willingness to communicate online on their commercial, ethical and 
social responsibilities. The results from the regression analysis reported positive and significant relationships between the SMEs' online stakeholder engagement and the pace of technological innovation; and between the SMEs' online engagement and the owner-managers' perceived usefulness of digital media. This study indicated that the pace of technological innovation, the owner-managers' perceived ease of use of the digital media, as well as their commercial responsibility were significant antecedents for their businesses' online communication of their responsible behaviors. Arguably, the use of technology is facilitated when individuals will perceive its usefulness and its ease of use (Davis, 1989). In fact, the findings from this research have specified that the owner-managers' intention was to use digital media to communicate about their responsible entrepreneurship. They also indicated their desire to use this innovation to engage with stakeholders on other topics, including commercial and ethical issues. This is in stark contrast with Penwar et al.'s (2017) findings, as the authors contended that the SME owner-managers' perceptions on social engagement did not hold the same virility when compared to the context of their larger counterparts. These authors argued that the tangible benefits of CSR engagement had no effect on SMEs. In a similar vein, Baumann Pauly et al.'s (2013) study reported that the larger businesses were more effective than SMEs in their CSR communications. However, the findings from this study's second, third and fourth regression equations indicated that the small and micro businesses were using digital media to improve their stakeholder engagement and to communicate about their responsible entrepreneurship issues.

\section{Implications and Conclusions}

SME managers and executives are in a position to enhance the effectiveness of their businesses' communication efforts. This study has identified and analyzed the SME owner-managers' attitudes toward the utilization of digital media for the communication of commercial, ethical and social responsibility issues. Previous academic research has paid limited attention to the technology acceptance of digital media among small businesses, albeit a few exceptions (Taiminen and Karjaluoto, 2015; Baumann Pauly, Wickert, Spence and Scherer, 2013; Durkin et al., 2013; Taylor and Murphy, 2004). In this case, the research findings indicated that digital technologies and applications were perceived as useful by the SME owner-managers. This implies that the utilization of digital media can be viewed as a critical success factor that may lead to an improved engagement with stakeholders.

Several SMEs are already communicating about their responsible entrepreneurship through conventional and interactive media, including; social media, review sites, blogs, et cetera. 
These savvy businesses are leveraging their communications as they utilize digital media outlets (e.g., The Guardian Sustainability Blog, CSRwire, Triple Pundit and The CSR Blog in Forbes among others) to improve their reach, frequency and impact of their message. In addition, there are instances where consumers themselves, out of their own volition are becoming ambassadors of trustworthy businesses on digital media (Du et al., 2010). Whilst other stakeholders may perceive these businesses' posturing behaviors and greenwashing (Camilleri, 2017; Vorvoreanu, 2009).

A thorough literature review suggested that the positive word-of-mouth publicity through digital media may lead to strategic and financial benefits (Camilleri, 2017; Taiminen and Karjaluoto, 2015; Durkin et al., 2013). Therefore, businesses, including SMEs, are increasingly joining conversations in social media networks and online review sites. These sites are being used by millions of users every day. Indeed, there is potential for SMEs to engage with their prospects and web visitors in real-time.

\subsection{Limitations of Study and Future Research Avenues}

Recently, there have been a few studies that have explored the entrepreneurial attitudes on stakeholder engagement and CSR reporting (Fassin, 2008; Murillo and Lozano, 2006). Yet, previous studies have considered different sampling frames, research designs, and methodologies. As a result, their findings have produced different outcomes.

This research has investigated the SME owner-managers' perceptions on stakeholder engagement via digital media. Although the number of survey participants was sufficient in drawing conclusions about their attitudes; this study is not amenable in drawing general conclusions in other contexts. Moreover, the majority of the survey respondents $(80 \%)$ were owner-managers of small firms having fewer than 50 employees. These participants were responsible for the marketing communications activities of their firms. However, they often performed other roles within their organization. This issue could have influenced the findings of this study. Generally, the results indicated that the SMEs' owner-managers were using digital media to promote their products and for stakeholder engagement purposes. Nevertheless, the descriptive statistics revealed that were a few respondents who were still apprehensive on the use of digital media.

Future studies can complement and improve this work in a number of ways. For instance, other research could include both small and large firms across various industries; to examine whether 
the effect of CSR communication is different between the two categories. Moreover, the researcher believes that there is scope in undertaking qualitative studies to explore the participants' in-depth opinions and perceptions on the subject. Further research is necessary to identify the organizational aspects that facilitate or hinder the implementation of CSR-practices and its communication. Knowledge about these aspects could inform and guide practitioners in both large and small firms. A longitudinal study in this area of research could possibly investigate the opportunities and threats of the consistent disclosures of responsible entrepreneurship through digital media, and to establish its reputational effects in the long run. Future research can specifically investigate the relevance of the SMEs' continuous engagement in online conversations with stakeholders.

\section{Acknowledgements}

The author thanks the General Retailers and Traders Union and the Malta Hotels and Restaurants Association for disseminating the survey questionnaire among their members, and for allowing the researcher to communicate about this research project in their annual event. The author also expresses his gratitude to the journal editor and to the reviewers for their constructive remarks and suggestions.

\section{References}

Bacon, N., Ackers, P., Storey, J. and Coates, D. (1996), "It's a small world: managing human resources in small businesses", International Journal of Human Resource Management, Vol. 7 No. 1, pp. 83-100.

Baden, D. and Harwood, I.A. (2013), “Terminology matters: A critical exploration of corporate social responsibility terms", Journal of Business Ethics, Vol. 116 No. 3, pp. 615-627.

Baumann-Pauly, D., Wickert, C., Spence, L.J. and Scherer, A.G. (2013), “Organizing corporate social responsibility in small and large firms: Size matters", Journal of Business Ethics, Vol. 115 No. 4, pp. 693-705.

Besiou, M., Hunter, M.L. and Van Wassenhove, L.N. (2013), "A web of watchdogs: Stakeholder media networks and agenda-setting in response to corporate initiatives", Journal of Business Ethics, Vol. 118 No. 4, pp. 709-729.

Brammer, S., Jackson, G. and Matten, D. (2012), "Corporate social responsibility and institutional theory: New perspectives on private governance", Socio-Economic Review. Vol. 10 No. 1, pp. 3-28. 
Brouthers, K. D., Nakos, G. and Dimitratos, P. (2015), "SME entrepreneurial orientation, international performance, and the moderating role of strategic alliances", Entrepreneurship Theory and Practice, Vol. 39 No. 5, pp. 1161-1187.

Camilleri, M.A. (2015), "Valuing stakeholder engagement and sustainability reporting", Corporate Reputation Review, Vol. 18 No. 3, pp. 210-222.

Camilleri, M.A. (2017), "Unlocking Corporate Social Responsibility Through Integrated Marketing Communication." In Corporate Sustainability, Social Responsibility and Environmental Management: An Introduction to Theory and Practice with Case Studies. Springer Nature, Cham, Switzerland, pp 41-59.

Capriotti, P. and Moreno, A. (2007), "Corporate citizenship and public relations: The importance and interactivity of social responsibility issues on corporate websites", Public Relations Review, Vol. 33 No. 1, pp. 84-91.

Castelló, I., Morsing, M. and Schultz, F. (2013), "Communicative dynamics and the polyphony of corporate social responsibility in the network society", Journal of Business Ethics, Vol. 118 No. 4, pp. 683-694.

Clarkson, M.E. (1995), "A stakeholder framework for analyzing and evaluating corporate social performance", Academy of Management Review, Vol. 20 No. 1, pp. 92-117.

Colleoni, E. (2013), "CSR communication strategies for organizational legitimacy in social media", Corporate Communications: An International Journal, Vol. 18, No. 2, pp. 228-248.

Davis, F.D. (1989), "Perceived usefulness, perceived ease of use, and user acceptance of information technology", MIS Quarterly, Vol. 13 No. 3, pp. 319-340.

Donaldson, T. and Preston, L.E. (1995), "The stakeholder theory of the corporation: Concepts, evidence, and implications", Academy of Management Review, Vol. 20 No. 1, pp. 65-91

Du, S., Bhattacharya, C.B. and Sen, S. (2010), "Maximizing business returns to corporate social responsibility (CSR, pp. The role of CSR communication", International Journal of Management Reviews, Vol. 12 No. 1, pp. 8-19.

Durkin, M., McGowan, P. and McKeown, N. (2013), "Exploring social media adoption in small to medium-sized enterprises in Ireland", Journal of Small Business and Enterprise Development, Vol. 20 No. 4, pp. 716-734.

Etter, M. (2013), "Reasons for low levels of interactivity: (Non-)interactive CSR communication in twitter", Public Relations Review, Vol. 39 No. 5, pp. 606-608.

Fassin, Y. (2008), "SMEs and the fallacy of formalizing CSR", Business Ethics: A European Review, Vol. 17 No. 4, pp. 364-378.

Fassin, Y., Van Rossem, A. and Buelens. M. (2011), "Small-business owner-managers' perceptions of business ethics and CSR-related concepts", Journal of Business Ethics, Vol. 98 No. 3, pp. 425-453. 
Fieseler, C. and Fleck, M. (2013), "The pursuit of empowerment through social media: Structural social capital dynamics in CSR-Blogging", Journal of Business Ethics, Vol. 118 No. 4, pp. 759-775.

Freeman, R.E. (1994), "The politics of stakeholder theory: Some future directions", Business Ethics Quarterly, Vol. 4 No. 4, pp. 409-421.

Fuller, T. and Tian, Y. (2006), "Social and symbolic capital and responsible entrepreneurship: an empirical investigation of SME narratives", Journal of Business Ethics, Vol. 67 No. 3, pp. 287-304.

Garcia, R. and Calantone, R. (2002), "A critical look at technological innovation typology and innovativeness terminology: a literature review", Journal of Product Innovation Management, Vol. 19 No. 2, pp. 110-132.

Greenhow, C. and Robelia. B. (2009), "Old communication, new literacies: Social network sites as social learning resources", Journal of Computer-Mediated Communication, Vol. 14 No. 4, pp. 1130-1161.

Grewal, R., Mehta, R. and Kardes, F.R. (2004), "The timing of repeat purchases of consumer durable goods: The role of functional bases of consumer attitudes", Journal of Marketing Research, Vol. 41 No. 1, pp. 101-115.

Gupta, P., Seetharaman, A. and Raj, J. R. (2013), "The usage and adoption of cloud computing by small and medium businesses", International Journal of Information Management, Vol. 33 No. 5, pp. 861-874.

Harrigan, P. and Miles, M. (2014), "From e-CRM to s-CRM. Critical factors underpinning the social CRM activities of SMEs", Small Enterprise Research, Vol. 21, No. 1, pp. 99-116.

Harris, L., Rae, A. and Misner, I. (2012), "Punching above their weight: the changing role of networking in SMEs", Journal of Small Business and Enterprise Development, Vol. 19 No. 2, pp. 335-351.

Jenkins, H. (2006), "Small business champions for corporate social responsibility", Journal of Business Ethics, Vol. 67 No. 3, pp. 241-256.

Kaplan, A.M. and Haenlein, M. (2010), "Users of the world, unite! The challenges and opportunities of Social Media”, Business Horizons, Vol. 53 No. 1, pp. 59-68.

Lamberton, C. and Stephen, A.T. (2016), "A Thematic Exploration of Digital, Social Media, and Mobile Marketing: Research Evolution from 2000 to 2015 and an Agenda for Future Inquiry”, Journal of Marketing, Vol. 80 No. 6, pp. 146-172.

Maranville, S. (1992), "Entrepreneurship in the Business Curriculum", Journal of Education for Business, Vol. 68 No. 1, pp. 27-31.

Matten, D. and Moon, J. (2008), "Implicit and explicit CSR: A conceptual framework for a comparative understanding of corporate social responsibility", Academy of Management Review, Vol. 33 No. 2, pp. 404-424. 
McWilliams, A. and Siegel, D. (2001), "Corporate social responsibility: A theory of the firm perspective", Academy of Management Review, Vol. 26 No. 1, pp. 117-127.

Meuter, M.L., Bitner, M.J., Ostrom, A.L. and Brown, S.W. (2005), "Choosing among alternative service delivery modes: An investigation of customer trial of self-service technologies", Journal of Marketing, Vol. 69 No. 2, pp. 61-83.

Moore, G. and Spence, L. (2006), "Responsibility and small business", Journal of Business Ethics, Vol. 67 No. 3, pp. 219-226.

Moreno, A. and Capriotti, P. (2009), "Communicating CSR, citizenship and sustainability on the web", Journal of Communication Management, Vol. 13 No. 2, pp. 157-175.

Morsing, M. and Schultz, M. (2006), "Corporate social responsibility communication: stakeholder information, response and involvement strategies", Business Ethics: A European Review, Vol. 15 No. 4, pp. 323-338.

Murillo, D. and Lozano, J.M. (2006), "SMEs and CSR: An approach to CSR in their own words”, Journal of Business Ethics Vol. 67 No. 3, pp. 227-240.

Orlitzky, M., Schmidt, F.L., and Rynes, S.L. (2003), "Corporate social and financial performance: A meta-analysis”. Organization Studies, Vol. 24 No. 3, pp. 403-441.

Orlitzky, M., Siegel, D.S. and Waldman, D.A. (2011), "Strategic Corporate Social Responsibility and Environmental Sustainability", Business and Society, Vol. 50 No. 1, pp. 627.

Panwar, R., Nybakk, E., Hansen, E. and Pinkse. J. (2015), "Does the business case matter? The effect of a perceived business case on small firms' social engagement", Journal of Business Ethics, Vol. 144 No. 3, pp. 597-608.

Perrini, F., Russo, A. and Tencati, A. (2007), "CSR strategies of SMEs and large firms. Evidence from Italy”, Journal of Business Ethics, Vol. 74 No. 3, pp. 285-300.

Rauniar, R., Rawski, G., Yang, J. and Johnson, B. (2014), "Technology acceptance model (TAM) and social media usage: an empirical study on Facebook", Journal of Enterprise Information Management, Vol. 27 No. 1, pp. 6-30.

Reijonen, H. (2010), "Do all SMEs practise same kind of marketing?", Journal of Small Business and Enterprise Development, Vol. 17 No. 2, pp. 279-293.

Russo, A. and Tencati, A. (2009), "Formal vs. informal CSR strategies: Evidence from Italian micro, small, medium-sized, and large firms", Journal of Business Ethics, Vol. 85, No. 2, pp. 339-353.

Russo, A., and Perrini, F. (2010), "Investigating stakeholder theory and social capital: CSR in large firms and SMEs", Journal of Business Ethics, Vol. 91 No. 2, pp. 207-221.

Schultz, F. and Wehmeier, S. (2010), "Institutionalization of corporate social responsibility within corporate communications: Combining institutional, sensemaking and communication perspectives", Corporate Communications: An International Journal, Vol. 15 No. 1, pp. 9-29. 
Schultz, F., Utz, S. and Göritz, A. (2011), "Is the medium the message? Perceptions of and reactions to crisis communication via twitter, blogs and traditional media", Public Relations Review, Vol. 37 No. 1, pp. 20-27.

Shah Alam, S. (2009), "Adoption of internet in Malaysian SMEs", Journal of Small Business and Enterprise Development, Vol. 16 No. 2, pp. 240-255.

Sin Tan, K., Choy Chong, S., Lin, B. and Uchenna, C.E. (2010), "Internet-based ICT adoption among SMEs: Demographic versus benefits, barriers, and adoption intention", Journal of Enterprise Information Management, Vol. 23 No. 1, pp. 27-55.

Singh, J. and Del Bosque, I.R. (2008), "Understanding corporate social responsibility and product perceptions in consumer markets: A cross-cultural evaluation", Journal of Business Ethics, Vol. 80 No. 3, pp. 597-611.

Spence, L.J. and Schmidpeter, R. (2003), "SMEs, social capital and the common good", Journal of Business Ethics, Vol. 45 No. 1, pp. 93-108.

Spence, L.J. (2007), "CSR and small business in a European policy context: the five "C" s of CSR and small business research agenda", Business and Society Review, Vol. 112 No. 4, pp. 533-552.

Storey, J., Emberson, C., Godsell, J. and Harrison, A. (2006), "Supply chain management: theory, practice and future challenges", International Journal of Operations and Production Management, Vol. 26 No. 7, pp. 754-774.

Taiminen, H.M., and Karjaluoto, H. (2015), "The usage of digital marketing channels in SMEs", Journal of Small Business and Enterprise Development, Vol. 22 No. 4, pp. 633-651.

Tantalo, C., and Priem, R.L. (2016), "Value creation through stakeholder synergy", Strategic Management Journal, Vol. 37 No. 2, pp. 314-329

Taylor, M. and Murphy, A. (2004), "SMEs and e-business", Journal of Small Business and Enterprise Development, Vol. 11 No. 3, pp. 280-289.

Tiago, M.T.P.M.B., and Veríssimo, J.M.C. (2014), "Digital marketing and social media: Why bother?”, Business Horizons, Vol. 57 No. 6, pp. 703-708.

Uhlaner, L.M., Van Goor-Balk, H.J.M., and Masurel, E. (2004), "Family business and corporate social responsibility in a sample of Dutch firms", Journal of Small Business and Enterprise Development, Vol. 11 No. 2, pp. 186-194.

Vorvoreanu, M. (2009), "Perceptions of corporations on Facebook: An analysis of Facebook social norms." Journal of New Communications Research, Vol. 4 No. 1, pp. 67-86. 